\title{
Surface current density K: an introduction
}

\author{
McAllister, lain Wilson
}

Published in:

IEEE Transactions on Electrical Insulation

Link to article, DOI:

10.1109/14.85112

Publication date:

1991

Document Version

Publisher's PDF, also known as Version of record

Link back to DTU Orbit

Citation (APA):

McAllister, I. W. (1991). Surface current density K: an introduction. IEEE Transactions on Electrical Insulation, 26(3), 416-417. https://doi.org/10.1109/14.85112

\section{General rights}

Copyright and moral rights for the publications made accessible in the public portal are retained by the authors and/or other copyright owners and it is a condition of accessing publications that users recognise and abide by the legal requirements associated with these rights.

- Users may download and print one copy of any publication from the public portal for the purpose of private study or research.

- You may not further distribute the material or use it for any profit-making activity or commercial gain

- You may freely distribute the URL identifying the publication in the public portal

If you believe that this document breaches copyright please contact us providing details, and we will remove access to the work immediately and investigate your claim 


\title{
SURFACE PHENOMENA
}

\section{Surface Current Density $\vec{K}$}

\author{
An Introduction
}

\author{
I. W. McAllister \\ Physics Laboratory II, \\ The Technical University of Denmark, Lyngby, \\ Denmark
}

\begin{abstract}
A $s$ far as electrical insulation studies are concerned,

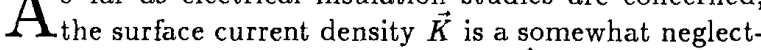
ed concept. On the occasions when $\vec{K}$ is introduced in textbooks, it is usually with reference to magnetic fields. If however one considers the insulation problems which arise on $\mathrm{HV}$ systems, owing to the pollution and contamination of components, it is clear that the concept of surface current density $\vec{K}$ should play an important role in such electrical insulation studies.
\end{abstract}

$\vec{K}$ is related to the tangential electric field strength $\vec{E}_{t}$ at the surface of a body by

$$
\vec{K}=\Gamma \vec{E}_{t}
$$

where $\Gamma$ represents the surface conductivity. From (1) it is clear that the basic SI units of $\vec{K}$ and $\Gamma$ are $\mathrm{A} / \mathrm{m}$ and $\mathrm{S}$, respectively.

The significance of $\vec{K}$ may be readily conveyed through a simple example. Consider a right circular-cylindrical spacer of radius $a$ in a uniform field gap. The spacer is assumed to have a homogeneous bulk conductivity $\gamma$ in addition to a homogeneous surface conductivity $\Gamma$. As the cylindrical surface will be tangential with the original field lines, such a spacer does not perturb the uniform $\vec{E}$ field. Consequently it is readily shown that the ratio of the bulk current $I_{B}$ to the surface current $I_{S}$ is given by

$$
\frac{I_{B}}{I_{S}}=\frac{\pi a^{2} \gamma E}{2 \pi a \Gamma E}=\frac{a \gamma}{2 \Gamma}
$$

From typical values given in the literature for epoxy, one obtains

$$
\frac{I_{B}}{I_{S}} \approx \frac{a}{1000}
$$

which for $a<1 \mathrm{~m}$ indicates that $I_{S}$ is the dominant current component. Alternatively, for current equality one requires $a \approx 1 \mathrm{~km}$. (Dimensions of this latter order of magnitude only arise with reference to cable insulation). A similar behavior to the above is exhibited by many insulating materials.

The basis of field solutions for time-dependent conduction current problems is the continuity equation

$$
\vec{\nabla} \cdot \vec{J}+\frac{\partial \rho}{\partial t}=0
$$

where $\vec{J}$ is the volume current density, $\rho$ the volume charge density and $t$ the time. To take account of surface currents, (4) must be expressed in relation to the relevant surface of discontinuity and the associated surface conductivity. This leads to an equivalent surface continuity equation, viz.

$$
\vec{n} \cdot \Delta \vec{J}+\vec{\nabla}_{S} \cdot \vec{K}+\frac{\partial \sigma}{\partial t}=0
$$

where $\sigma$ is the surface charge density.

The term $\vec{n} \cdot \Delta \vec{J}$ represents the interface divergence of $\vec{J}$ and is defined as

$$
\vec{n} \cdot \Delta \vec{J} \equiv \vec{n} \cdot\left(\vec{J}_{+}-\vec{J}_{-}\right)
$$

where the signs + and - refer to each side of the interface, respectively, and $\vec{n}$ is a unit vector normal to the interface and directed away from the positive side.

The term $\vec{\nabla} s \cdot \vec{K}$, or Div $\vec{K}$, represents the surface divergence of $\vec{K}$, which is defined as [1]

$$
\vec{\nabla}_{S} \cdot \vec{K} \equiv \lim _{\Delta A \rightarrow 0}\left[\frac{1}{\Delta A} \int_{c} \vec{K} \cdot \vec{m} d s\right]
$$

where $\vec{m}$ is an outward-directed unit vector normal to the closed curve $c$ and tangential to the surface in question.

0018-9367/91/0600-416\$1.00 (C) 1991 IEEE 
The curve $c$ bounds the elemental surface area $\Delta A$, and $s$ is a distance coordinate along $c$.

In essence, the surface continuity equation represents the boundary condition which the potential distributions in the adjoining media must fulfill. As discussed above, the volume current may be small in comparison to the surface current, and consequently in deriving the potential solutions the first term in (5) can sometimes be neglected.

As discussed in [2], inhomogeneities in $\gamma$ lead to an accumulation of volume charge in the bulk material. Similarly, inhomogeneities in $\Gamma$ lead to an accumulation of surface charge. The derivation of the variation in $\sigma$ is however a more involved analysis than that for the $\rho$ variation, see Discussion in [2]. The surface conductivity of an insulator is usually strongly influenced by the local environment of the insulator, see $[3,4]$, and hence an inhomogeneous $\Gamma$ variation is liable to be the norm, rather than the exception. As a consequence of (5), it should be noted that, surface charge accumulation can also occur with a constant $\Gamma$ if $\vec{n} \cdot \Delta \vec{J} \neq 0$.

Finally for situations in which $\partial \sigma / \partial t=0,(5)$ reduces to give the steady-state boundary condition to be employed in the solution of either Laplace's equation or Poisson's equation for the conduction field.
In conclusion, this brief introduction to the concept of surface current density $\vec{K}$ is intended to stimulate an awareness of the concept, and as a consequence lead to its greater utilization in insulation studies, for which surface conductivity undoubtedly plays a major role.

\section{REFERENCES}

[1] E. Martensen, Potentialtheorie, B. G. Teubner Stuttgart, pp. 72-75, 1968.

[2] I. W. McAllister and G. C. Crichton, "Analysis of the Temporal Electric Fields in Lossy Dielectric Media", IEEE Trans. Elect. Insul., Vol. 26, this issue, 1991.

[3] B. M. Weedy, "DC Conductivity of Voltalit Epoxy Spacers in $\mathrm{SF}_{6}$ ", IEE Proc. A, Vol. 132, pp. 450-454, 1985.

[4] J. M. Braun, F. Y. Chu and R. Seethapathy, "A Surface Resistivity Probe for Assessing Solid Insulators in GIS", Conference Record of the 1990 International Symposium on Electrical Insulation, IEEE Publication 90CH2727-6, pp. 439-442, 1990.

Manuscript was received on $17 \mathrm{June} 1991$ 